\title{
USING MULTIMEDIA IN E-LEARNING, A NEW ROLE FOR TEACHERS?
}

\author{
Everardo Reyes García and Imad Saleh \\ Laboratiore Paragraphe, Université Paris VIII \\ 2 rue de la liberté, 93526, Saint Denis Cedex02 \\ Tel. +33.1.49.40.67.89. Fax. +33.1.48.21.04.46 \\ FRANCE \\ everardo.reyes@itesm.mx saleh@labart.univ-paris8.fr
}

\begin{abstract}
This document presents a general overview of a new role proposed for teachers who are in contact with the information and communication technologies for distance courses content creation: the teacher-developer role. To acquire this profile, we are developing at the Laboratoire Paragraphe (Universit_Paris 8, France) and the Tecnológico de Monterrey Campus Toluca (Mexico) a software tool called HyperTectol that introduces guides and promote in the faculty the use of multimedia elements for the Learning Objects design and creation.
\end{abstract}

Key words: learning objects, teacher-developer, multimedia elements, course content creation, new pedagogy

\section{THE PROBLEM}

Some authors consider that well-designed Web-based teaching systems can greatly enhance student learning, while decreasing the amount of time spent in traditional classroom lectures.

In face of those changes, we consider that teachers who are in touch with information and communication technologies should start getting involved with the use of multimedia resources in education. An adequate process would consist of an introduction for those teachers who haven't had any 
previous experience in the domain of e-learning, which could then be gradually complemented until satisfactory immersion in the area is reached.

\section{HYPERTECTOL}

At the Université Paris 8 we are developing an assistant tool for creating and authoring course content. Its target public are teachers with little or no previous experience in the area who want to work out their immediate needs, but, most important, who want to start a process of promoting multimediabased culture for pedagogic content design.

Our tool is called "HyperTectol" and its goal is to introduce, guide and promote the faculty members to the use of multimedia elements for the Learning Objects design and creation for delivery through web.

Our research proposes a first step towards a new role called the teacherdeveloper, who has two main characteristics: 1) basic knowledge of how to create multimedia-based course content, and 2) domain expertise in his area of study.

We divided the said process into three stages or levels: beginner, intermediate and advanced. Each level offers faculty members different perspectives for using multimedia resources in online courses. Each of these phases also has a section that allows users to design, create and edit LO. Media types vary form one stage to the other, gradually increasing; starting with text, continuing on to images and sound and finishing with video and animation.

At this moment, we consider that the main limitations of Hypertectol are related to its interface, which is presented in English and the platform required is Mac OS X (10.2 or later). Coming versions consider XML technologies, French and Spanish interfaces, and an online version accessible from the Web. 